\title{
Evolution of cigarette
}

\section{Commentary}

Cigarette smoking is so common within the world's population and prevalence has increased markedly over also the popularity of electronic nicotine delivery systems and electronic non-nicotine delivery systems (ENDS/ENNDS) are rapidly increasing the past decades in many countries over the world. Indeed, cigarette smoking and e-cigarettes using are pandemic have huge implications for public health. ${ }^{1}$ In recent years, as the number of smokers worldwide is reaching record highs and anti-smoking policies are proliferating, several new products are being launched by the industry of alternative smoking products with hopes for increasing market shares and revenues. One of the most popular products in the market is the ENDS/ ENNDS. There is growing interest and concern about e-cigarettes in many countries because e-cigarettes have been widely advertised in many countries in the past few years, mostly through the internet. Distributors of e-cigarettes promote the product as completely free of harmful substances. Nonetheless, some distributors present their products as an alternative to tobacco smoking, suggesting that e-cigarettes can be used to aid smoking cessation. ${ }^{2}$

Tobacco and tobacco products has a long history in the world are back to somewhere between 600 to 900 A.D. That time the Mayan Indians of Mexico carved drawings in stone showing tobacco use. In the 16th century, the consumption, cultivation, and trading of tobacco quickly spread and after that the first commercial cigarettes were made in $1865 .^{3}$ After that rates of cigarette smoking widely increase throughout the world. Inventor Herbert A. Gilbert who on presented invention in 1963 and patented in 1965 that represent the main characteristics of e-cigarettes from United States Patent Office the name of smokeless nontobacco cigarette. E-cigarettes industries have a latent period forty years from 1963 to 2003 . The history of e-cigarette then restarted in 2003. From Chinese pharmacist Hon Lik invention of e-cigarettes that is a first prototype of uses a lithium battery to produce energy to vaporize glycerol and a nicotine solution through a piezoelectric device. Between the 1963-2003 forty years global e-cigarette market was show a four decade latent period. After latent period tobacco industry present a new born cigarette technology which is e-cigarette. Latent period might have a basic three reasons. These are technologically readiness, users psychologically readiness, preparing the marketing strategy. Technologically readiness means invent the smart smoker that more usable, more lightweight and have a more product option for users/smokers. Users psychologically readiness is that need to be psychologically readiness of smokers/ users this new technology because of smokers or users not ready to use this new technology. If e-cigarette compared with convantional cigarette, e-cigarette using not easier than conventional cigarette. Preparing the marketing strategy means that be situated next generation e-cigarettes in global market. Users/smokers must be ready to use this new technology. After that time export began in 2005-2006. In 2015 year, the most recently progress is a new generation products of tobacco industries. Especially a world's largest tobacco companies are phasing out cigarettes with its new non-burning alternatives such as a IQOS ${ }, \operatorname{PLOOM} \AA$, VOKE $®$ that are not a traditional cigarette, not an e-cigarette. ${ }^{4-7}$

During the past few years e-cigarettes have been gaining popularity, also future perspectives of the tobacco industry in the face of the
Volume 5 Issue 5 - 2017

\section{Gülșen Göney \\ Department of Toxicology, Gazi University, Turkey}

Correspondence: Gülșen Göney, Department of Toxicology, Faculty of Pharmacy, Gazi University, Turkey, Tel +90 0537250 22 07, Fax +90 312222 2326, Email gulsengoney@gmail.com

Received: April 21, 2017| Published: May 05, 2017

fast growing market of e-cigarettes and technological development, industrial growth, changing user demands are caused represent of new product such as next generation e-cigarettes in global market. ${ }^{8,9}$ In addition, the market may change since the tobacco industry has launched alternative nicotine delivery systems that heat but do not burn tobacco and is developing or has bought nicotine inhaler technology that does not require a heating mechanism alternatives as a IQOS $\AA$, PLOOM ${ }^{\circledR}, \operatorname{VOKE}{ }^{\circledR} .^{10}$

Innovations, technological breakthroughs and many changes in industry at the and the result of impressive improvement in global tobacco industries cigarette that finalized its evolution give way to by stages in multiple generations of e-cigarettes that are first, second, third, fourth and next generation cigarettes. Distributors of e-cigarettes promote the product as completely free of harmful substances. Nonetheless, some distributors present their products as an alternative to tobacco smoking, suggesting that e-cigarettes can be used to aid smoking cessation. The benefits and risks of e-cigarette use are uncertain as the technology is relatively new. Moreover, no sufficient scientific evidence is available confirming the safety and efficacy of e-cigarette's which is needed for helping the decisions of consumers and regulators. ${ }^{11-13}$

ENDS are in the world wide largely unregulated and internet sales are substantial. It's known that tobacco and tobacco products are harmful for human health. Even restriction by the law did not stop usage of tobacco products but when the material dimension of tobacco industry considered despite of their damages it continued to exist. As matter of fact in the second decade of the new millennium cigarette that finalized its evolution gives way to the new generation technological cigarettes we called the e-cigarettes.

\section{Acknowledgements}

None.

\section{Conflict of interest}

Author declares that there is no conflict of interest.

\section{References}

1. Adkison SE, O’Connor RJ, Bansal-Travers M, et al. Electronic nicotine delivery systems: international tobacco control four-country survey. $\mathrm{Am}$ J Prev Med. 2013;44(3):207-215. 
2. Bullen $\mathrm{C}$, Howe $\mathrm{C}$, Laugesen $\mathrm{M}$, et al. Electronic cigarettes for smoking cessation: a randomised controlled trial. The Lancet. 2013;382(9905):1629-1637.

3. Jacobs M. From the First to the Last Ash: The History, Economics \& Hazards of Tobacco: a Comprehensive Adult Basic Education Curriculum. Community Learning Center. 1997.

4. Lik H. Flameless electronic atomizing cigarette. United States patent application. 2004.

5. Gilbert H. Smokeless non-tobacco cigarette. USA; 1965.

6. Fairchild AL, Bayer R, Colgrove J. The renormalization of smoking? E-cigarettes and the tobacco "endgame". New England Journal of Medicine. 2014;370(4):293-295.

7. CASAA. Electronic Cigarettes. 2015.

8. Farsalinos KE, Spyrou A, Tsimopoulou K, et al. Nicotine absorption from electronic cigarette use: comparison between first and newgeneration devices. Sci Rep. 2015;5:11269.
9. Das S, Tonelli M, Ziedonis D. Update on Smoking Cessation: E-Cigarettes, Emerging Tobacco Products Trends, and New TechnologyBased Interventions. Curr Psychiatry Rep. 2016;18(5):51.

10. Protano C, Manigrasso M, Avino P, et al. Second-hand smoke exposure generated by new electro-nic devices (IQOS $®$ and e-cigs) and traditional cigaret-tes: submicron particle behaviour in human respiratory system. Annali di igiene: medicina preventiva e di comunità. 2016;28(2):109-112.

11. Electronic Nicotine Delivery Systems and Electronic Non-Nicotine Delivery Systems (ENDS/ENNDS). India: WHO; 2016.

12. Goniewicz ML, Kuma T, Gawron M, et al. Nicotine levels in electronic cigarettes. Nicotine Tob Res. 2013;15(1):158-166.

13. Goniewicz ML, Knysak J, Gawron M, et al. Levels of selected carcinogens and toxicants in vapour from electronic cigarettes. Tobacco control. 2014;23(2):133-139. 